\title{
Spatially distributed stimuli show little effect of recency with either visual or auditory presentation
}

\author{
SUSAN KARP MANNING, TERESA WISEMAN, SERGIO MARINI, and WILMA TORRES \\ Hunter College and the Graduate School, City University of New York, New York, New York
}

\begin{abstract}
The effect of recency-the superior recall of final as opposed to middle items in serial presentation-is usually greater for auditorily as opposed to visually presented stimuli. However, the standard method of presenting both visual and auditory stimuli consists of temporal presentation in a single location. Having used a new procedure, in which stimuli were spatially distributed, Battacchi, Pelamatti, and Umiltà (1990) reported a robust effect of visual recency in immediate serial recall, similar to that found with auditory stimuli. Their subjects were native speakers of Italian. To test and explain these findings, we performed three experiments with native speakers of English as subjects. The stimuli were letters of the alphabet and vowel-consonant syllables; presentations were both auditory and visual. The results suggest that the spatial distribution of stimuli does not produce a major recency effect in the visual modality and leads to a smaller recency effect with auditory stimuli than that usually found in the standard presentation condition. Finally, in Experiment 3, the use of native speakers of Italian as subjects demonstrated that the difference in the subjects' language is not a factor in the discrepancy between our findings and those of Battacchi et al.
\end{abstract}

The recency effect consists of the superior recall of final as opposed to middle items on a list. Past research has consistently shown that the recency effect is greater for auditorily as opposed to visually presented stimuli (e.g., Frick, 1988; Glenberg \& Swanson, 1986; Manning, Koehler, \& Hampton, 1990; Nairne, 1988), particularly in serial recall. In fact, auditory stimuli tend to produce $U$ shaped serial position curves in serial recall tasks, whereas visual stimuli either produce J-shaped curves, with a minimal recency effect, or no recency effect at all (Greene, 1987; Manning \& Schreier, 1988; Penney, 1989). This superior recall of auditory as opposed to visual stimuli is known as the modality effect.

For many years, Crowder and Morton's (1969) theory was used to explain the modality effect. They postulated that auditory traces are relatively long-lived, whereas visual traces are relatively short-lived. The recency effect is thus explained by the subject's use of the extra information available in auditory as opposed to visual sensory traces.

Experiment 1 was conducted by W.T. as part of honors research. She was supported by a Minority Biomedical Research Support Grant to S.K.M., Associate Investigator on an NIH institutional grant to Hunter College. Experiment 2 was conducted as part of honors research by T.W. Experiment 4 was performed by S.M., also as part of honors research. He recruited native Italian speakers in the New York area and conducted Experiment 4 in Italian. The results from Experiments 1 and 2 were presented at the Meeting of the Eastern Psychological Association, Boston, April 1992. Experiment 3 was presented at the Meeting of the Eastern Psychological Association, Arlington, VA, April 1993. Correspondence concerning this paper should be addressed to S. K. Manning, Department of Psychology, Hunter College, 695 Park Avenue, New York, NY 10021.
Recent work has presented both challenges and exceptions to Crowder and Morton's (1969) theory, which assumes the auditory specificity of recency effects. The most reliable exceptions to the auditory-visual differences have been found with the use of lip-read stimuli. Such stimuli generally produce an effect of recency that is similar to that produced by auditory stimuli (see, e.g., Campbell \& Dodd, 1984; Greene \& Crowder, 1984).

Although the modality effect is extremely strong and consistent (see, e.g., Frankish, 1989; Frick, 1988; Glenberg \& Swanson, 1986; Manning et al., 1990; Nairne, 1988; Penney, 1989), no adequate explanation exists for it or for the similar effects with lip-read stimuli.

One apparent challenge to the standard modality effect can be found in the recent work of Battacchi, Pelamatti, and Umiltà (1990). It has been argued that the auditory system is inherently superior at coding temporal information, whereas the visual system is superior at coding spatial information (see, e.g., Gardiner, 1983; Glenberg \& Swanson, 1986; Metcalfe, Glavanov, \& Murdock, 1981). This argument is supported by studies which suggest that the modality effect is weakened when subjects are not instructed to recall the items in their order of occurrence (strict serial recall vs. free recall) (Murdock \& Walker, 1969).

The preceding hypothesis led Battacchi et al. (1990) to perform two experiments to test whether distributing visual items spatially would increase the effect of recency at the end of the sequence. In all of their experiments, they utilized conditions in which the subjects were required to serially recall six-item lists constructed from the syllables PE, PI, and PU. 
In Experiment 1, there were four conditions. In the first two, subjects were required to read the stimuli, which appeared in the center of a computer screen one at a time, aloud and silently, respectively. As is standard with this paradigm, these conditions led to a normal modality effect.

In the third condition, Battacchi et al. (1990) presented the stimuli both sequentially and horizontally across the computer screen. That is, Item 1 appeared in the first position on the far left, Item 2 appeared in the second position, and so forth; Item 6 , the last item, appeared in the sixth position on the far right. In the fourth condition, vertical sequential presentation was employed, with the stimuli in serial order from the top to the bottom of the screen. Conditions 3 and 4 provided the subject with both temporal and spatial cues, whereas Conditions 1 and 2 , which were the standard conditions, provided only temporal cues.

As expected, Conditions 1 and 2 produced a standard modality effect. However-and this was the important finding - a robust recency effect was obtained in both Conditions 3 and 4 , in which the stimuli were horizontally and vertically presented and spatially distributed.

Not unexpectedly, these findings led to further research in other laboratories, including ours. LeCompte (1992) examined the effect of spatially distributing visual lists of items and failed to replicate the findings of Battacchi et al. (1990); he used digits rather than syllable sets. In the final experiment in his series, LeCompte attempted to replicate Battacchi et al.'s experiment as closely as possible. The stimuli, the experimental design, the timing, and the procedure were identical. The language of the subjects, however, was English rather than Italian. No sizable recency effect was apparent.

In a series of four experiments, we attempted to learn more about sequential temporal presentation of stimuli in visual and auditory presentations. In so doing, we partially overlapped some aspects of Battacchi et al.'s (1990) research and that of LeCompte (1992); we performed the present Experiments 1 and 2 before we learned about LeCompte's work. However, we also have some new data that sheds further light on the processing of stimuli in Battacchi et al.'s paradigms.

\section{EXPERIMENT 1}

Single letters of the alphabet that were minimally confusable and that should, if anything, increase the effect of recency were used.

\section{Method}

Subjects. Twelve Hunter College students, whose first language was English, participated in the experiment.

Experimental design. Stimuli, consisting of randomly generated letters that were maximally discriminable (J, H, R, L, M, S, Q) both auditorily and visually according to the Manning (1977) norms, were presented on a computer screen.

The stimuli were arranged to form six lists of 10 sequences each. The sequences were random, except that each letter appeared only once in each sequence, no consecutive sequences had the same letter in the same serial position, and no consecutive sequences began or ended with the same letter.

The following three experimental conditions were employed: center screen temporal (CST), which was the standard control condition; hor-
Table 1

Mean Number of Items Recalled as a Function of Serial Position in Three Presentation Conditions in Experiment 1

\begin{tabular}{cccccccc}
\hline & \multicolumn{7}{c}{ Serial Position } \\
\cline { 2 - 8 } Condition & 1 & 2 & 3 & 4 & 5 & 6 & 7 \\
\hline HT & 8.88 & 6.83 & 5.96 & 5.79 & 5.33 & 4.71 & $5.33^{*}$ \\
HS & 9.63 & 8.54 & 8.25 & 7.83 & 6.92 & 5.92 & $6.79 *$ \\
CST & 8.67 & 6.54 & 6.13 & 5.67 & 4.92 & 4.88 & $5.46 \dagger$ \\
\hline
\end{tabular}

Note-HT, horizontal temporal; HS, horizontal simultaneous; CST, center screen temporal. Maximum number correct $=10 . \quad p<.05$. $\dagger p<.10$.

izontal temporal (HT), which was the Battacchi et al. (1990) condition; and simultaneous (S) presentation. The sequentially presented stimuli appeared on the screen for $.5 \mathrm{sec}$ and were then off for $.5 \mathrm{sec}$ in the CST and HT conditions. In the $S$ condition, the stimuli appeared across the screen simultaneously for a period of $6.5 \mathrm{sec}$. Thus, the length of presentation for each trial corresponded to the lengths from start to finish of the other experimental conditions.

Condition (CST, HT, and S) was combined with free and serial recall instructions to form a counterbalanced factorial design.

Procedure. The subjects read the letters silently without mouthing them. Recall began after presentation of the last stimulus. The subjects were instructed to write from left to right, recalling the letters in the order of presentation, without backtracking. If they could not recall a letter, they were asked to guess. Answers were written on a prepared answer sheet.

\section{Results and Discussion}

Because of a methodological problem with the free recall condition, it was omitted from analysis. Because the design was counterbalanced, an analysis of variance was performed to determine whether order effects for the recall conditions or interactions of order with other variables were present. This resulted in a 2 (order: serial recall first, serial recall second) $\times 3$ (conditions: CST, HT, S) $\times 7$ (serial position) design.

Neither the main effect of order nor any of the interactions of order with the other variables was significant (all $F \mathrm{~s}<1$ ). Thus, we felt justified in analyzing the results of the data independently of this condition.

Table 1 shows the means of the correct answers in the serial recall condition, as a function of condition and serial position. A response was scored correct only if the correct letter appeared in the correct serial position. These means indicate that the effect of recency was small and not comparable to that found in auditory presention or reported by Battacchi et al. (1990).

The presence of a minimal effect of recency was tested with matched $t$ tests to compare performance on Position 6 with that on Position 7 in the S, HT, and CST conditions $[\operatorname{ts}(23)=2.21,2.07$, and 1.64 , respectively $]$. Although the first two conditions showed a significant effect of recency and the third a marginally significant effect $(p<.06)$, these effects are not comparable in magnitude to the usual auditory effects or the findings of Battacchi et al. (1990).

\section{EXPERIMENT 2}

Experiment 2 was a further attempt to examine the unusual findings of Battacchi et al. (1990) more closely. In this experiment, we employed the horizontal and vertical 
presentations used in the last condition of Experiment 1 in Battacchi et al.'s paper, a new recall method, and the same stimuli as those in Experiment 1 of the present paper.

HT and vertical temporal (VT) stimulus arrays and center screen presentation were each paired with horizontal recall (HR) and vertical recall (VR) to form six experimental conditions. Thus, in addition to matched conditions (e.g., HT presentation-HR), there were crossed conditions (e.g., HT presentation-VR).

\section{Method}

Subjects. The subjects were 24 Hunter College students. All spoke English as their first language.

Experimental Design and Procedure. Three stimulus presentation methods were employed, an HT condition that was identical to Battacchi et al.'s (1990) condition in which the stimuli were spatially arrayed from left to right on the computer screen; a VT condition, in which the stimuli were spatially arrayed vertically in a single column at the center of the computer screen in the same way as in Battacchi et al.; and the standard CST condition, in which stimuli were presented according to the standard method, one at a time at the center of the screen. These three presentation methods were crossed with two recall methods. The first, HR, required the subjects to write their responses from left to right; the second, VR, required the subjects to write their responses from top to bottom. Thus, there were six conditions: (1) HT-HR, (2) HT-VR, (3) VT-HR, (4) VT-VR, (5) CST-HR, and (6) CST-VR. Conditions 1 and 3 were direct replications of Battacchi et al. In Conditions 2, 4, and 6, presentation was opposite to that in the recall condition.

The stimuli were the same as those in Experiment 1. As before, they were arranged to form 60 different random sequences, each containing every letter once in random order. These 60 sequences were made into six lists of 10 sequences each. All subjects received all six conditions and all six stimulus lists. Four different $6 \times 6$ balanced Greco-Latin Squares were used to generate the presentation orders and lists.

The subjects were tested in the same manner as in Experiment 1 . The instructions were the same as in Experiment 1, except when recall was vertical.

\section{Results and Discussion}

As can be seen in Table 2, which gives the mean number correct for all serial positions for all conditions, a small significant recency effect was present for the CST presentation in both HR and VR $[t \mathrm{~s}(23)=2.74$ and 3.34 , respectively]. In addition, a slight recency effect was present for the HT presentation with VR and the VT presentation with $\mathrm{HR}[t \mathrm{~s}(23)=3.50$ and 3.59 , respectively]. Finally, recency was not significant in the HT presentation with HR or the VT presentation with VR $[t s(23)=$

Table 2

Mean Number of Items Recalled as a Function of Serial Position, Three Presentations and Horizontal or Vertical Recall in Experiment 2

\begin{tabular}{cccccccl} 
Presentation & \multicolumn{7}{c}{ Serial Position } \\
\cline { 2 - 8 } $\begin{array}{c}\text { and Recall } \\
\text { Condition }\end{array}$ & 1 & 2 & 3 & 4 & 5 & 6 & \multicolumn{1}{c}{7} \\
\hline HT-HR & 9.33 & 8.29 & 8.12 & 7.92 & 7.62 & 6.79 & 7.12 \\
VT-VR & 9.46 & 8.62 & 8.46 & 7.79 & 7.12 & 6.62 & $7.71^{*}$ \\
HT-HR & 9.25 & 8.37 & 8.08 & 7.75 & 6.92 & 6.92 & $7.83^{*}$ \\
VT-VR & 9.21 & 8.29 & 7.92 & 7.79 & 6.96 & 7.17 & 7.33 \\
CS-HR & 9.50 & 8.21 & 7.62 & 7.79 & 7.25 & 6.96 & $7.71^{*}$ \\
CS-VR & 9.21 & 8.62 & 8.54 & 8.21 & 7.21 & 6.96 & $8.17^{*}$ \\
\hline
\end{tabular}

Note-HT, horizontal temporal; VT, vertical temporal; CST, center screen temporal; HR, horizontal recall; VR, vertical recall. *Significant recency $(p<.05)$.
1.21 , for both conditions]. The last two findings are probably a result of the generally small recency effect found in this paradigm as opposed to the differences found between crossed and congruent conditions.

\section{EXPERIMENT 3}

In Experiment 3, we utilized both visual and auditory conditions. As far as we know, no one had studied Battacchi et al.'s (1990) methods of presentation in both the visual and the auditory modalities or the effects of phonological similarity on recall in this type of paradigm.

Further, after considering our results and those of LeCompte (1992), there seemed to be only one alternative left as to why substantial visual recency might be present in Battacchi et al.'s (1990) study and not in the work in our laboratory or that of LeCompte. Battacchi et al.'s subjects spoke Italian as their native language, whereas our subjects and those of LeCompte spoke English as their native language. Thus, it was decided to run a set of conditions similar to those utilized in our previous work, with the only difference being the language in which the experiment was performed and, of course, the native language of the subjects. As in Battacchi et al.'s research, our subject pool consisted of native speakers of Italian. Additionally, as before, we varied auditory cofusability.

\section{Method}

Subjects. The subjects were 16 native speakers of Italian living in New York City.

Experimental design and Procedure. All stimuli were presented visually on a computer screen. As in Experiment 3, the stimuli were single letters or consonant/vowel combinations. The stimuli chosen were PE, PI, PU; TA, GA, MA; and H, S, M, Q, L, R. The stimuli were randomly generated to form 48 sequences of six letters or six vowel/consonant sets. These sequences were made into six lists of eight sequences.

The stimuli were presented at the center of the screen (CST) or horizontally (HT), as described in the previous experiments. The subjects participated in both the visual and the auditory conditions and received all stimulus lists.

The entire experiment was translated into Italian. Both the experimenter, a native speaker of Italian, and the subjects spoke Italian throughout the session. The actual instructions were the same as in Experiments 1 and 2 for the visual condition. For the auditory condition, the subjects were instructed to read the stimuli aloud as they appeared on the screen.

All conditions were counterbalanced. Unlike in Experiments 1 and 2 , the stimuli were presented for $.200 \mathrm{msec}$ with a .300 -msec interstimulus interval. This was the same presentation rate used by Battacchi et al. (1990). The subjects were given $10 \mathrm{sec}$ for recall.

\section{Results and Discussion}

The data in this study were analyzed by using a method from Manning and Robinson (1989). Because the numbers of items making up a set of stimuli differed, chance performance differed when there were six as opposed to three stimuli in a stimulus set. Sets consisting of three items were corrected by taking the proportion out of eight correct and substracing $1 / 3(.33)$, the proportion correct by chance in the absence of any knowledge of the correct stimulus and using this as the numerator. The denominator was $2 / 3(.67)$, the residual that remains when chance performance is subtracted from $1(1-.33=.67)$. Sets of six 
Table 3

Corrected Means for Serial Positions 5 and 6 as a Function of Presentation Modality and Presentation Condition in Experiment 4

\begin{tabular}{|c|c|c|c|c|c|c|c|c|}
\hline \multirow[b]{3}{*}{ Stimuli } & \multicolumn{4}{|c|}{ Auditory } & \multicolumn{4}{|c|}{ Visual } \\
\hline & \multicolumn{2}{|c|}{ CST } & \multicolumn{2}{|c|}{ HT } & \multicolumn{2}{|c|}{ CST } & \multicolumn{2}{|c|}{ HT } \\
\hline & 5 & 6 & 5 & 6 & 5 & 6 & 5 & 6 \\
\hline PE PI PU & .59 & $.80 *$ & .58 & .64 & .59 & .62 & .57 & .59 \\
\hline H S M Q L & .53 & $.65^{*}$ & .64 & .72 & .43 & .50 & .50 & .60 \\
\hline PA BA TA & .37 & .37 & .42 & .47 & .38 & .45 & .32 & $.46 *$ \\
\hline
\end{tabular}

Note-CST, center screen temporal; HT, horizontal temporal. *Significant recency $(p<.05)$.

items were corrected similarly, except that $1 / 6(.17)$ was subtracted from the proportion correct to form the numerator and $(1-.17)$ or .83$)$ was used as the denominator.

The numbers reported in Table 3 give the corrected proportion of performance above chance for Positions 5 and 6. The effect of recency was tested with matched $t$ tests as in Experiments 1 and 2.

The means for Positions 5 and 6 are shown in Table 3. In the center screen auditory condition, a significant recency effect was obtained with the dissimilar stimuli $(\mathrm{H}$, S, M, Q, L, R) and the Battacchi et al. (1990) stimuli (PE, PI, PU), but not with the similar stimuli (PA, BA, TA). No visual conditions show significant recency. In the HT condition, the significance obtained with the visually presented PA, BA, TA was probably due to random effects. However, no other conditions show a reliable effect of recency. It should be noted that both performance and the modality effect were somewhat diminished.

Thus it appears that the results with Italian speaking subjects are virtually the same as those with English speaking subjects.

\section{GENERAL DISCUSSION}

The effect of spatially distributing visual and auditory list items was examined in three experiments. Spatial temporal presentation of stimuli did not produce a consistently large recency effect in the visual modality, although a minimal recency effect was present in some situations. The stimuli in Experiment 1 were rated as being highly distinct visual stimuli (Manning, 1977), which, if anything, should have increased the recency effect. This research supports that of LeCompte (1992), in the failure to replicate the findings of Battacchi et al. (1990) with the use of other distinct stimuli.

In Experiment 2, in addition to again failing to find a recency effect with the use of horizontally presented stimuli, we failed to find it with vertically presented stimuli. Thus, we were unable to replicate a second condition from Battacchi et al.'s (1990) study.

In Experiment 3, phonologically similar and dissimilar stimuli were compared by using visual and, for the first time, auditory presentation with spatially distributed stimuli. Although a modality effect was present, the visual conditions again produced minimal recency. The auditory recency effect was less than normal, although it was greater than in the visual modality. Phonological similarity did not appear to have the same role in reducing the recency effect with auditory presentation as has usually been found (e.g., Darwin \& Baddeley, 1974; Manning \& Robinson, 1989). This may suggest that the spatial distribution of the stimuli causes more reliance on visual factors.
Additionally, and more important, in Experiment 3, we replicated our findings with visual stimuli by using a study run in Italian. We used the same timing, the same stimuli, and the same language as did those in Battacchi et al. (1990). Thus, the use of the Italian language in Experiment 3 eliminated the possibility that anything about this language, as compared with English, caused the recency effect in the spatial temporal condition.

Thus, we remain unable to explain the similarities between the work in this labortory and that of LeCompte (1993), and the differences that exist in the work of Battacchi et al. (1990).

\section{REFERENCES}

Battacchi, M., Pelamatti, G. M., \& Umiltà, C. (1990). Is there a modality effect? Evidence for visual recency and suffix effects. Memory \& Cognition, 18, 651-658.

Campbell, R., \& Dodd, B. (1984). Aspects of hearing by eye. In H. Bouma \& D. G. Bouwhuis (Eds.), Attention and performance X: Control of language processes (pp. 299-312). Hillsdale, NJ: Erlbaum.

Crowder, R. G., \& Morton, J. (1969). Precategorical acoustic storage (PAS). Perception \& Psychophysics, 5, 365-373.

DARWIN, C. J., \& BADDELEY, A. D. (1974). Acoustic memory and the perception of speech. Cognitive Psychology, 6, 41-60.

FrANKISH, C. (1989). Perceptual organization and precategorical acoustic storage. Journal of Experimental Psychology: Learning, Memory, \& Cognition, 15, 469-479.

FrICK, R. W. (1988). Issues of representation and limited capacity in the auditory short-term store. British Journal of Psychology, 79, 213-240.

GaRDINER, J. M. (1983). On recency and echoic memory. Philosophical Transactions of the Royal Society of London, 302, 267-282.

Glenberg, A., \& SWANSON, N. G. (1986). A temporal distinctiveness model of recency and the modality effects. Journal of Experimental Psychology: Learning, Memory, \& Cognition, 12, 3-15.

GREENE, R. L. (1987). Stimulus suffixes and visual presentation. Memory \& Cognition, 15, 497-503.

Greene, R. L., \& Crowder, R. G. (1984). Modality and suffix effects in the absence of auditory stimulation. Journal of Verbal Learning \& Verbal Behavior, 23, 371-382.

LECoMPTE, D. C. (1992). In search of a strong visual recency effect. Memory \& Cognition, 20, 563-572.

MANNING, S. K. (1977). Ratings of the auditory and visual similarity of consonants: Implications for research. Behavior Research Methods \& Instrumentation, 9, 495-498.

Manning, S. K., Koehler, L., \& Hampton, S. (1990). The effects of recoding and presentation format on recency and suffix effects. Memory \& Cognition, 18, 164-173.

MANning, S. K., \& Robinson, I. I. (1989). Recency and suffix effects as a function of auditory confusability and set size. American Journal of Psychology, 102, 495-510.

MANNing, S. K., \& Schreier, H. (1988). Recency and suffix effects as a function of recall method. American Journal of Psychology, 101, 97-109.

Metcalfe, J., Glavanov, D., \& Murdock, M. (1981). Spatial and temporal processing in the auditory and visual modalities. Memory \& Cognition, 9, 351-359.

MURDOCK, B. B., JR., \& WALKeR, K. D. (1969). Modality effects in free recall. Journal of Verbal Learning \& Verbal Behavior, 8, 665-676.

NAIRNE, J. S. (1988). A framework for interpreting recency effects in immediate serial recall. Memory \& Cognition, 16, 343-352.

PenNey, C. G. (1989). Modality effects and the structure of short-term verbal memory. Memory \& Cognition, 17, 398-422.

(Manuscript received July 1, 1993.) 